\title{
Mate availability and male dispersal in the Argentine ant Linepithema humile (Mayr) (= Iridomyrmex humilis)
}

\author{
LUC PASSERA* \& LAURENT KELLER $\dagger$ \\ *Laboratoire d'Ethologie et Psychologie animale, URA CNRS 1837 Université Paul-Sabatier, \\ 31062 Toulouse Cedex, France \\ $\dagger$ †oologisches Institut, Bern University, Ethologische Station Hasli, Wohlenstrasse 50a, \\ 2732 Hinterkappelen, Switzerland, and Institut de Zoologie et d'Ecologie Animale, \\ University of Lausanne, Bâtiment de Biologie, 1015 Lausanne, Switzerland
}

(Received 6 April 1993; initial acceptance 27 May 1993; final acceptance 8 July 1993; MS. number: 4357)

\begin{abstract}
In the Argentine ant Linepithema humile (=Iridomyrmex humilis) only males disperse whereas female sexuals (unmated winged queens) stay in their mother nest where they mate. This study investigated (1) whether dispersing males are accepted into foreign colonies, (2) whether they can mate with resident female sexuals, and (3) whether the propensity of males to disperse is affected by the expectation of mating in their mother nest. Field experiments demonstrated that males were accepted into foreign colonies only when these colonies contained female sexuals or queen pupae. Before and after the time of produ fen $\lrcorner$ le sexuals, workers attacked and killed most of the foreign males. Laboratory experiments sinowed that males that successfully enter foreign colonies can mate with resident female sexuals. The propensity of males to disperse was significantly influenced by the presence of female sexuals in their nest. Males were more likely to fly out from colonies containing no female sexuals than from those with them. These results are consistent with males preferentially dispersing when there is little or no opportunity to mate in their mother nest. Thus there are two mating strategies available for males: staying in their mother nest when an opportunity to mate arises or dispersing and attempting to mate in a foreign nest when there are no female sexuals in their mother nest. This latter behaviour could mediate gene flow between colonies and account for the lack of significant inbreeding previously documented in this species.
\end{abstract}

A critical feature of the reproductive biology of ants is the departure of male and female sexuals (young unmated queens) on a mating flight (Hölldobler \& Wilson 1990, pp. 145-157). In addition to its importance for the insemination of females, the mating flight serves two main functions. First, it provides an effective means of dispersal, since females can fly or be carried long distances by wind; second, it is probably the primary mechanism preventing inbreeding. Winged males and females of many ant species emerge from large numbers of nests simultam neously and fly before mating, thus greatly decreasing the probability of close relatives contacting one another (Crozier 1980).

In several ant species, however, females (and sometimes males) have reduced dispersal abilities and mating occurs within the colony (e.g. the Argentine ant Linepithema humile previously Iridomyrmex humilis: Newell \& Barber 1913;
Keller \& Passera 1992; Monomorium pharaonis: Petersen \& Buschinger 1971; Lasius sakagamii: Yamauchi et al. 1981; several Formica species: Fortelius et al. 1993). Because nestmates are often highly related in ants, it is generally assumed that within-nest mating results in inbreeding (Yamauchi et al. 1991). This is true for monogynous (single-queen) colonies in which males and female sexuals are siblings. However, virtually all of the non-parasitic species in which nestmate sexuals copulate within the nest (and all those mentioned above) are polygynous (colonies contain several functional queens). In polygynous colonies, the level of inbreeding might be low if colonies contain many unrelated queens or if sexuals preferentially mate with unrelated individuals and there is gene flow between colonies.

In a separate study (Keller \& Passera 1993) we investigated whether inbreeding avoidance occurs 
in the highly polygynous Argentine ant L. humile. Queens of this species generally mate in the nest a few days after eclosion from the pupae (Passera \& Keller 1992). Males have frequently been observed in mating flights and/or captured in aerial traps (Newell \& Barber 1913; Benois 1973), whereas females do not participate in a mating flight (Passera \& Keller 1990). Mate-choice experiments showed that sibling mating was rare when female sexuals were presented simultaneously with a brother and an unrelated male (Keller \& Passera 1993). Our aim in the present study was to investigate the second component affecting the degree of inbreeding in species exhibiting within-nest mating, namely if consistent gene flow between colonies can be achieved by males dispersing between colonies.

Combining field and laboratory experiments, we show here that $L$. humile males can successfully disperse and mate with female sexuals in foreign colonies. Thus males have the option of either remaining in their natal colony and trying to mate with nestmate female sexuals or dispersing and trying to enter a foreign colony. The probability of males mating with a nestmate queen is dependent on the numerical sex ratio in their mother colony. The overall numerical sex ratio is highly male-biased $(10 \cdot 1: 1)$, and both sexes mate effectively only once (Keller \& Passera 1992). Thus only a small proportion of the males can secure a mate, and this proportion is lower when the sex ratio in the colony is more male-biased. Since the numerical sex ratio varies greatly between colonies, with a significant proportion containing no female sexuals (Keller \& Passera 1992), it is interesting to know whether males in colonies with more heavily male-biased sex ratios preferentially disperse. We investigated this by comparing the patterns of male dispersal in colonies with and without female sexuals.

\section{MATERIALS AND METHODS}

\section{Source of Ants}

All colonies of L. humile originated from the same local population of Port-Leucate on the Southern Mediterranean coast of France. Each colony was collected by digging $1-2 \mathrm{~m}^{2}$ of sand which was brought to the laboratory where the ants were slowly drawn out of the soil with the aid of a $100 \mathrm{~W}$ incandescent lamp. We collected colonies that were at least $100 \mathrm{~m}$ apart so that they were foreign to each other; it is highly improbable that workers, queens or brood move and merge with a colony more than a few metres away. The colonies were kept in the laboratory following standard procedures (Passera et al. 1988). Both the ants and the experimental units used for the mating experiments (see below) were maintained in the laboratory $\left(28 \pm 2^{\circ} \mathrm{C}, 16: 8 \mathrm{~h}\right.$ light:dark regime). All colonies were fed the same artificial diet (Keller et al. 1989) and given sugar water. Experimental colonies were set up immediately after the colonies were collected from the field. All field experiments were also conducted in Port-Leucate.

Under our laboratory conditions males are frequently produced in colonies containing small numbers of queens. All these males develop from queen-produced eggs since in this species workers cannot produce viable eggs (Passera et al. 1988). Because males readily mate with nestmate female sexuals, all queen pupae were removed from the colonies producing both sexes in order to prevent such unwanted matings from occurring.

\section{Ability of Males to Disperse and Survive}

We carried out two experiments. In the first we determined the proportion and age of dispersing males. Groups of 5-15 males (depending on the number of males available) $0-24$ h old were trans. ferred to experimental parental queenless units $(N=18)$ and the number of males dispersing determined for 66 days (after which time all males had flown out or died). In a second experiment we investigated the ability of males to survive out of their mother colony by isolating 20-25 males about 10 days old (at which age males are most likely to depart on mating flights) in small plastic boxes ( $85 \mathrm{~mm}$ diameter; $N=5$ ). Each box was closed with a lid, to prevent the males from flying out, and provided with a wet sponge as a source of water. Every day, the dead males were counted and removed, and a drop of sugar water was deposited in each colony.

\section{Ability of Males to Enter Foreign Colonies}

Because there is generally a high density of workers around the colony entrance, males can enter foreign colonies only if they are not attacked by workers (unpublished data). We conducted two experiments males are attack and if not, whe these colonies. and males were (all nests were le experiment, mals available) were immediately tras (85 mm diamete from another co We recorded agg the males, depos and the number introduction to ments showed $t$ varied according colonies, with a contained sexuals ments at four diff cycle of the colo replicates), at wh produced but no were present in replicates), at $\mathrm{w}$ numerous female 7 June (five replic of female sexuals and colonies cont 17 June (10 replic: sexuals but no mo the colonies; and which time the col but no more quee

Both in the la frequently observe typical way they $u$ We therefore hyp may enter foreign porting them. We ment by taking immediately releas of another colon increase the prob: males and workers of plastic were dep The two plastic pie prevent workers a sides. Males (7-25 available) were de diameter), which w and we recorded 
$00 \mathrm{~m}$ apart so that they it is highly improbable rood move and merge few metres away. The e laboratory following sera et al. 1988). Both ntal units used for the elow) were maintained $2^{\circ} \mathrm{C}, 16: 8 \mathrm{~h}$ light:dark fed the same artificial and given sugar water. re set up immediately ollected from the field. re also conducted in

onditions males are freonies containing small ese males develop from in this species workers ss (Passera et al. 1988). e with nestmate female vere removed from the exes in order to prevent om occurring.

\section{se and Survive}

eriments. In the first we and age of dispersing ales (depending on the ) $-24 \mathrm{~h}$ old were transarental queenless units males dispersing deterhich time all males had second experiment we males to survive out of isolating 20-25 males ich age males are most flights) in small plastic $N=5$ ). Each box was at the males from flying et sponge as a source of ad males were counted $\mathrm{p}$ of sugar water was

\section{Foreign Colonies}

ally a high density of ny entrance, males can if they are not attacked data). We conducted two experiments in the field to investigate whether males are attacked by workers in foreign colonies, and if not, whether they can successfully enter these colonies. In these experiments all workers and males were taken from the same population (all nests were less than $150 \mathrm{~m}$ apart). In the first experiment, males ( $7-25$ depending on the number available) were taken from their colony and immediately transferred into small plastic boxes ( $85 \mathrm{~mm}$ diameter) containing 50 workers collected from another colony located at least $100 \mathrm{~m}$ away. We recorded aggression by workers (e.g. biting of the males, deposition of chemicals on the males) and the number of dead males $5 \mathrm{~h}$ after their introduction to the boxes. Preliminary experiments showed that the aggression of workers varied according to the reproductive cycle of the colonies, with a much lower level when colonies contained sexuals. We therefore conducted experiments at four different periods of the reproductive cycle of the colonies in 1992: on 19 May (nine replicates), at which time adult males had been produced but no queen pupae or female sexuals were present in the colonies; on 4 June (seven replicates), at which time colonies contained numerous female sexuals and queen pupae; on 7 June (five replicates), at which time the number of female sexuals in the nests started to decrease and colonies contained only few queen pupae; on 17 June (10 replicates), at which time a few female sexuals but no more queen pupae were present in the colonies; and on 29 June (eight replicates), at which time the colonies still contained adult males but no more queen pupae or female sexuals.

Both in the laboratory and in the field we frequently observed workers carrying males in the typical way they usually carry larvae and pupae. We therefore hypothesized that dispersing males may enter foreign colonies through workers transporting them. We tested this in a second experiment by taking males from colonies and immediately releasing them on the foraging trail of another colony (about $100 \mathrm{~m}$ away). To increase the probability of encounters between males and workers, two curved (half circle) pieces of plastic were deposited on each side of the trail. The two plastic pieces were coated with fluon to prevent workers and males from climbing the sides. Males (7-25 depending on the number available) were deposited in this arena $(30 \mathrm{~cm}$ diameter), which was crossed by the worker trail, and we recorded the proportion of males that
(1) walked out of the arena, (2) were carried back to the nest by workers, or (3) were attacked by workers. These experiments were also carried out at different times of the reproductive cycles, i.e. when numerous female sexuals were present in the nests (11 June 1991, one replicate and 2 June 1992, two replicates), when the number of female sexuals in nests started to decrease (7 June 1992, five replicates), and when the nests contained no more female sexuals (17 June 1991, one replicate and 26 June 1992, two replicates).

\section{Male Survival in Foreign Colonies}

We investigated whether males that have successfully entered a foreign nest can survive and mate with resident females. In a first set of experiments we compared male survival in three types of colonies: (1) 15 males were introduced into queenless foreign colonies $(N=10)$ containing 100 workers; (2) males were introduced into queenless foreign colonies $(N=10)$ containing virgin female sexuals and 100 workers, with the number of males introduced depending on the number of female sexuals (five males per female sexual; two to three female sexuals per colony); (3) $15-20$ males were kept in colonies $(N=10)$ containing 100 workers and a few mated queens originating from the same colony. All these colonies were housed in boxes $(28 \times 28 \times 16 \mathrm{~cm})$ without openings to prevent the males from leaving and we recorded daily the number of males that died in each colony. To avoid a possible effect of the origin of the males, equal numbers of males from several source colonies were always transferred to the same number of each of the three types of experimental colonies.

\section{Ability of Males to Mate in Foreign Colonies}

The ability of males to mate in foreign nests was investigated under laboratory conditions. Two large colonies producing female sexuals were collected on 20 June 1990. Another colony producing males was collected on the same day ca $50 \mathrm{~m}$ away. Inmediately after returning to the laboratory we counted the number of female sexuals in the two queen-producing colonies and removed all queen pupae (there were no males in these colonies and dissection of female sexuals showed they were all unmated). We then introduced into the foraging arena of these two colonies males 
collected from the male-producing colony. A total of 250 males were introduced into the two colonies between 25 and 30 June 1990. We recorded whether the males were attacked by workers, or whether they walked (or were carried by the workers) into the nest. About 2 weeks after the introduction of the males we collected all the female sexuals as well as those that had dropped their wings and dissected them to determine their mating status. Unmated female sexuals can be easily differentiated from mated ones because their spermathecae are transparent rather than opaque white (Keller \& Passera 1992).

\section{Alternative Male Mating Strategies}

This experiment investigated the effect of the presence of female sexuals on the propensity of males to disperse. Twenty-five males (of unknown age) were transferred to colonies $(N=7)$ containing no female sexuals or to colonies $(N=7)$ containing five nestmate female sexuals less than $24 \mathrm{~h}$ old. To avoid a possible effect of the origin of the males, males from a given colony were always transferred simultaneously to colonies with and without female sexuals. To investigate the pattern of male dispersal, colonies (ca 1300 workers) were kept in plastic boxes (130 mm diameter) whose sides were coated with fluon thus preventing workers and males from climbing the sides. However, males could disperse on the wing since the boxes were open. Each box was surrounded by water and enclosed in a large wire mesh cage $(28 \times 28 \times 16 \mathrm{~cm})$. Males dispersing on the wing landed on the water where they died. The number of dead males in the water (dispersers) and living males in their colony (non-dispersers) was counted daily. Seven days after the beginning of the experiment all female sexuals were dissected to determine their mating status (Keller \& Passera 1992).

\section{Statistical Analyses}

Percentages and proportions were square-root arcsine transformed to obtain normal distributions (Sokal \& Rohlf 1980). All ANOVAs and multiple comparisons were performed on these transformed values. Multiple comparisons between pairs of means were carried out using Scheffé F-tests (Sokal \& Rohlf 1980). Unless otherwise mentioned, means are given \pm SD.

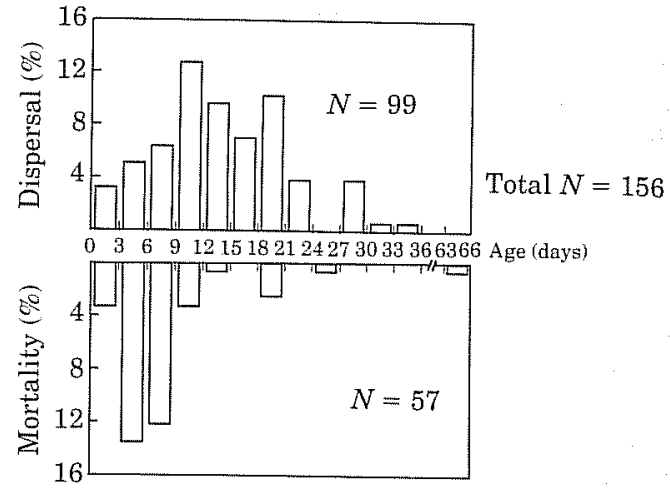

Figure 1. Number of males dispersing versus number of males dying in their mother nest as a function of age.

\section{RESULTS}

\section{Ability of Males to Disperse and Survive}

When raised in colonies containing no female sexuals, $63 \%(N=99)$ of the males flew out of the colony within 36 days of eclosion from the pupae (Fig. 1). There was great variability in the age at which males flew. Most of them flew between days 3 and 21, with a majority of flights recorded between days 9 and 21 ( $66 \%$ of the flights). All but one of the males $(N=57)$ that did not fly died before the age of 27 days. The majority of them (79\%) died before 9 days, that is before most of the males that flew. The average age of males that died in the colonies ( 8.5 days old, including the male that died at age 63-66 days) was significantly lower than that of males departing for a mating flight (14.1 days; Mann-Whitney $U$-test (twotailed): $z=5 \cdot 77, N=156, P<0 \cdot 001)$.

The ability of males to survive out of their mother colony was demonstrated in the experiment where males that were ca 10 days old were kept without workers. Most of them were able to survive several days $(7 \cdot 6 \pm 2 \cdot 6, N=133$; Fig. 2) thus providing them with an opportunity to find a colony to enter (see below).

\section{Ability of Males to Enter Foreign Colonies}

In the first experiment, worker behaviour towards males varied with the time of the reproductive cycle of the colonies $\left(F_{4,42}=66.7\right.$, $P<0.001$, arcsine transformations; Fig. 3). When workers were presented with males before any female sexuals were present in the colonies they

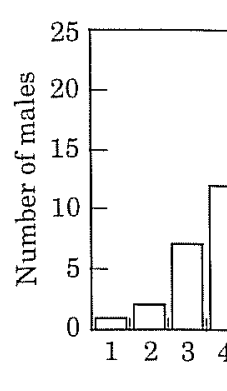

Figure 2. Mortality without workers.

strongly attacked ive interaction wa single male was $k$ was carried out female sexuals we proportion of mal rently with the de sexuals in the colc maximal when present in the $\mathrm{c}$ killed $80 \%$ of the

When males $\mathrm{w}$ by a foraging tre frequently grabbe carried them bac males were viol killed by workers males walked or attacked or carrie

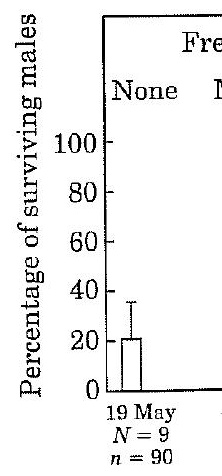

Figure 3. Percentag in the presence o number of replicat presented to worke reproductive cycle female sexuals pre 


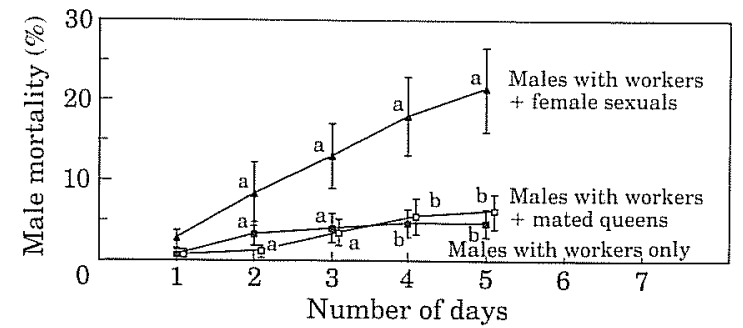

Figure 5. Mortality $(\bar{X} \pm \mathrm{SE})$ of males in queenless foreign colonies with and without virgin female sexuals and in colonies with nestmate workers and queens. Treatments with different lower case letters differed significantly at a particular week $(P<0 \cdot 05$, Scheffé-test square-root transformation). $N=10$ for each week and each treatment.

"on day 5 , a value significantly higher (Scheffétest $=4 \cdot 24, P<0.05$ ) than in foreign colonies containing no female sexuals $(4 \cdot 7 \%)$ and colonies where males were kept with nestmate queens and workers $(6 \cdot 2 \%)$. These data suggest that males are successfully accepted into foreign colonies but that more die in colonies containing female sexuals probably because males died after mating (see below). There were 26 female sexuals in the 10 units and 130 males were introduced into these units. Since males and queens successfully mate only once in this species (Keller \& Passera 1992), $20 \%(26 / 130)$ of the males must have died after mating if all queens mated. Thus the higher mortality of males in colonies containing female sexuals could be accounted for if most of the queens mated and if most of the males died soon after mating.

That males frequently die after mating was shown in the experiment where female sexuals were presented with several males for $24 \mathrm{~h}$. In 88 of these trials one male successfully mated with the queen and $25(28.4 \%)$ were found dead at the end of the 24-h experiment. In contrast, the mortality among males that did not mate was more than 13 times lower: only eight $(2 \cdot 1 \%)$ of the 383 unsuccessful males were found dead $\left(\chi^{2}=0 \cdot 80\right.$, $d f=2, \quad P<0.001)$. Video recording showed that queens generally bite males violently to end mating (see Keller \& Passera 1992), thus possibly wounding them. Only exceptionally, however, did this biting immediately kill the male and in most cases the male died a few hours to 2 days after mating. Thus, post-mating male mortality is certainly much higher than $30 \%$, since this value reflects only the proportion of males killed during the 24-h experiment (i.e. between 0 and $24 \mathrm{~h}$ after mating). It should be mentioned that there is no selective advantage for males to survive after mating since they mate only once (they have degenerate testes and discharge all their sperm during a single mating; see Keller \& Passera 1992; Passera \& Keller 1992).

\section{Ability of Males to Mate in Foreign Colonies}

Whether males can effectively reproduce in foreign colonies was investigated in the laboratory by introducing males into the foraging area of two colonies containing female sexuals. As in the field experiments conducted when female sexuals were present in the colonies, no aggression by workers towards males was observed and most of the males were carried to the nest by workers (a small proportion of them walked on their own to the nest). Two weeks after the introduction of the males, $50 \%$ of the queens in both types of colonies were missing (Table I). The high mortality of queens is a general phenomenon in this species and is not associated with the introduction of foreign males (Passera \& Aron 1993). Twenty-two $(48 \%)$ of the surviving queens were mated, indicating that the foreign males successfully mated with resident queens (Table I). All the surviving queens that mated had shed their wings, whereas only five $(21 \%)$ of the 24 queens that did not mate had shed their wings, indicating that mating triggers wing shedding (see also Passera et al. 1988).

\section{Alternative Male Mating Strategies}

The proportion of males that flew was significantly affected by the presence of female sexuals (Fig. 6). In colonies containing female sexuals, only $15 \cdot 4 \%$ of the males flew during the first 2 days, whereas $54.3 \%$ of the males flew from colonies containing no female sexuals (Mann-Whitney $U$-test (two tailed): $z=3 \cdot 14, N=122, P<0 \cdot 002$ ). A
Table I. Initial number o from a foreign colony

\begin{tabular}{lc} 
Nest & $\begin{array}{c}\text { Initial number } \\
\text { female sexua }\end{array}$ \\
\hline 1 & 47 \\
2 & 45 \\
Total & 92
\end{tabular}

higher proportion of and 5 in colonies cont ever, when this value tion of males present the proportion of ma colonies with female without $(24 \cdot 9 \%)$, indi female sexuals had an males to disperse on of the experiment.

\section{DISC}

Our results show that perse, enter foreign $n$ female sexuals. Other foreign colonies have ants such as army a 1987). This behaviour ponerine ants lacking In these species, sexua wingless ergatoid que less queens with a sim workers (gamergates)

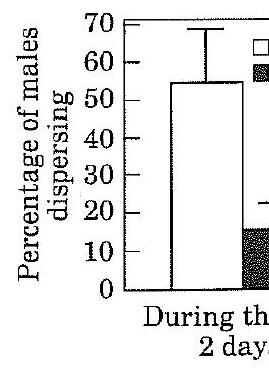

Figure 6. Percentage of $n$ after their introduction sexuals $(N=7)$ and colon $(N=7 ; 25$ males per colo 
Table I. Initial number of female sexuals and reproductive status of those alive 2 weeks after males were introduced from a foreign colony

in female sexuals and in differed significantly at a nd each treatment.

nly once (they have harge all their sperm Keller \& Passera 1992;

\section{Foreign Colonies}

ectively reproduce in gated in the laboratory ne foraging area of two sexuals. As in the field on female sexuals were aggression by workers ved and most of the est by workers (a small 1 on their own to the e introduction of the both types of colonies the high mortality of menon in this species $\mathrm{h}$ the introduction of ron 1993). Twenty-two ens were mated, indiles successfully mated e I). All the surviving $\mathrm{d}$ their wings, whereas leens that did not mate ating that mating trigo Passera et al. 1988).

\section{trategies}

that flew was signifience of female sexuals aining female sexuals, lew during the first 2 males flew from colonxuals (Mann-Whitney $N=122, P<0.002)$. A

Reproductive status of the surviving queens

\begin{tabular}{lcccccr}
\cline { 5 - 6 } Nest & $\begin{array}{c}\text { Initial number of } \\
\text { female sexuals }\end{array}$ & $\begin{array}{c}\text { Number of } \\
\text { males introduced }\end{array}$ & $\begin{array}{c}\text { Total } \\
\text { number alive }\end{array}$ & $\begin{array}{c}\text { Wingless } \\
\text { and mated }\end{array}$ & $\begin{array}{c}\text { Wingless } \\
\text { and unmated }\end{array}$ & $\begin{array}{c}\text { Winged } \\
\text { and unmated }\end{array}$ \\
\hline 1 & 47 & 135 & 20 & 9 & 2 & 9 \\
2 & 45 & 115 & 26 & 13 & 3 & 10 \\
Total & 92 & 250 & 46 & 22 & 5 & 19 \\
\hline
\end{tabular}

higher proportion of males flew between days 3 and 5 in colonies containing female sexuals; however, when this value is expressed as the proportion of males present in the colony after day 2 , the proportion of males flying is very similar in colonies with female sexuals $(25.7 \%)$ and those without $(24.9 \%)$, indicating that the presence of female sexuals had an effect on the propensity of males to disperse only during the first 2 days of the experiment

\section{DISCUSSION}

Our results show that males can successfully disperse, enter foreign nests and mate with resident female sexuals. Other examples of males entering foreign colonies have been recorded in some other ants such as army ants (Franks \& Hölldobler 1987). This behaviour is also frequent among the ponerine ants lacking a queen caste (Peeters 1991). In these species, sexual reproduction is assigned to wingless ergatoid queens (i.e. permanently wingless queens with a simplified thorax) or to mated workers (gamergates). In both cases, of course,

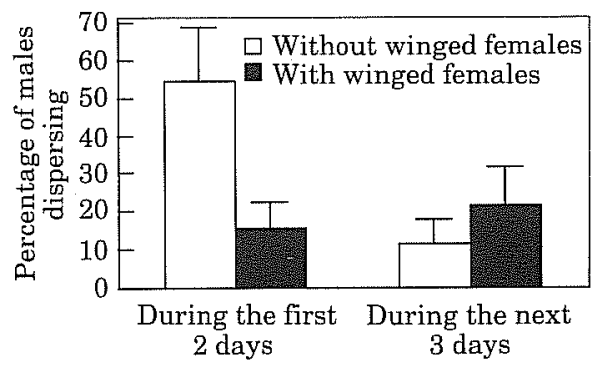

Figure 6. Percentage of males that flew during the 5 days after their introduction into colonies containing female sexuals $(N=7)$ and colonies containing no female sexuals $(N=7 ; 25$ males per colony). females are unable to fly so the males leave the mother nest on the wing, locate foreign nests and mate with ergatoids or gamergates inside or near the entrance. Females of these species apparently mate only with foreign males. This contrasts with L. humile where under natural conditions males entering a foreign colony generally have to compete with resident males to mate with resident female sexuals. That dispersing males may successfully compete with resident males is supported by the fact that female sexuals showed no preference when presented simultaneously with two unrelated males, one from their own colony and the other from another one (Keller \& Passera 1993). Furthermore, our experiments show that males live as long in foreign colonies as in their own colony, thus suggesting that males in foreign colonies have the same amount of time to secure a mate.

An interesting finding of this study is that colonies accept males only during the short period when they produce sexuals. There are two possible and not mutually exclusive explanations for the association between the acceptance of foreign males and the presence of sexuals in colonies. First, accepting foreign males has been selected as a means to increase genetic diversity within the colony. Such inter-colonial gene flow coupled with preferential mating with unrelated individuals may be an effective mechanism to avoid inbreeding in species exhibiting within-nest mating (see below). Second, foreign males are accepted because workers are unable to discriminate them from nestmate males. Many highly polygynous species such as $L$. humile exhibit no inter-colonial aggression (Passera 1994). Nevertheless, although workers originating from distant sites are not aggressive to each other, they display particular exploratory behaviour towards non-nestmates indicating the existence of nestmate recognition 
abilities (Kaufmann \& Passera 1991). Furthermore, Kaufmann \& Passera (1991) showed that in the laboratory the condition of the colonies influenced worker behaviour towards foreign males, when these were presented: workers from queenless colonies (thus producing sexuals see Passera et al. 1988; Vargo \& Passera 1991) accepted foreign males, whereas workers from queenright colonies (thus producing no sexuals; see Passera et al. 1988; Vargo \& Passera 1991) attacked and killed males. Taken together, these results support the hypothesis that workers accept foreign males as a means of increasing colony genetic diversity.

Two components are important in determining the level of inbreeding associated with within-nest mating. The first is the effective number of queens producing sexuals and their genetic relatedness, with genetic relatedness among queens being lower the more gene flow there is between colonies. The second is the preferential mating between related or unrelated individuals in a colony. As mentioned earlier, inbreeding avoidance has been shown to occur in L. humile; female sexuals avoid mating with their brother when presented simultaneously with an unrelated male (Keller \& Passera 1993). The results of the present study show that gene flow between colonies may occur via male dispersal. To some extent it may also occur by female sexuals or mated queens dispersing from one nest to another, but the dispersal range of queens is probably limited since they never fly. That gene flow between colonies, coupled with preferential mating between unrelated individuals, provides an effective mechanism of inbreeding avoidance is supported by genetic data showing no significant level of inbreeding in the same population where colonies were collected (Kaufmann et al. 1992).

When raised in colonies containing no queen pupae or female sexuals, a significant proportion $(37 \%)$ of males died without fiying. The majority of the males that did not fly died when they were less than 9 days old, whereas the mean age of males flying was $14 \cdot 1$ days. This suggests that the lack of flight by some males results from their early death rather than a dispersal polymorphism. Why so many males die during the 9 days after eclosion is not known. Data on L. humile female sexuals provide a similar pattern with $20 \%$ of them dying during the 4 days following eclosion (Passera \& Aron 1993).
Male propensity to disperse was contextdependent, with higher dispersal in colonies containing no female sexuals. Dispersal is probably risky since predation by birds, spiders, insects, and other ant species during flight and the time before they locate a foreign colony is likely to be significant. Predation is indeed known to be high during the mating flight in other ant species (Whitcomb et al. 1973; Hölldobler \& Wilson 1990). Thus, whether males benefit from dispersing depends on the risk of harmful inbreeding in the case of within-nest mating and the relative probabilities males have to secure a mate in the natal and a foreign colony. As mentioned earlier, the probability of males mating in their mother colony depends on the numerical sex ratio in the colony. Thus, the more the sex ratio is male-biased in a colony compared with the overall sex ratio in the population, the more likely the males should be to disperse. The present study compared the propensity of males to disperse between colonies containing no female sexuals and colonies with a $1: 5$ male-biased sex ratio, i.e. about half as malebiased as colonies in the field (see Keller \& Passera 1992). In the laboratory the proportion of males dispersing in the colonies with female sexuals was significantly lower than in colonies without female sexuals during the first 2 days of the experiment. After 2 days most, or possibly all, the female sexuals were mated and the proportion of males flying was similar in both types of colony. These data are consistent with males preferentially dispersing when there is little opportunity for mating in their colony. Interestingly, available field evidence suggests that males may disperse only, or mainly, in colonies containing no female sexuals. Several authors have monitored the timing of mating flights by males in L. humile field populations both in California (Bartels 1983) and in France (Benois 1973). In both populations a higher proportion of mating flights occurred late in the reproductive season when many nests probably no longer contained female sexuals. In fact male dispersal tactics may be influenced by the presence of not only female sexuals but also queen pupae. Because males are long-lived (see Results) they may benefit by not dispersing if their nest contains queen pupae. Consistent with this hypothesis is the observation that only a few mating flights occur early in the reproductive season when adult males and queen pupae, but no winged queens, are present in the colonies ( 1992).

In conclusion, successfully ente resident female ant species, mat ably risky, whi dispersal by ma little expectatio males is probab nents of gene concert with $\mathrm{p}$ related sexuals, preventing inbr within-nest mati

ACK

We thank Andr Edward L. Var manuscript. We the Swiss Natior 0283650 and 31 Pöhn Stiftung l'Environnemen Midi-Pyrénées (

Bartels, P. J. 19 biology of the $A$ of California at Benois, A. 1973. sur le cycle a fourmi d'Arge (Hymenoptera, d'Antibes. Insed

Crozier, R. H. 19 population. In: esis and Empiri. 146. Weinheim

Fortelius, W., Ro D. 1993. Quee supercolony of Formicidae). $O$

Franks, N. R. \& tion during colc Linn. Soc, 30 ,

Hölldobler, B. \& Springer-Verlag

Kaufmann, B. \& du problème Iridomymex in Actes Coll. Inse 
pperse was contextersal in colonies conDispersal is probably s, spiders, insects, and at and the time before is likely to be signifiown to be high during nt species (Whitcomb Wilson 1990). Thus, dispersing depends on eding in the case of relative probabilities te in the natal and a ned earlier, the probtheir mother colony ex ratio in the colony. tio is male-biased in a overall sex ratio in the the males should be to compared the propentween colonies containd colonies with a $1: 5$ - about half as maleId (see Keller \& Passera he proportion of males with female sexuals was colonies without female days of the experiment. ossibly all, the female he proportion of males types of colony. These males preferentially disopportunity for mating agly, available field evis may disperse only, or ining no female sexuals. onitored the timing of in L. humile field popua (Bartels 1983) and in In both populations a mating flights occurred season when many nests ntained female sexuals. actics may be influenced only female sexuals but use males are long-lived benefit by not dispersing queen pupae. Consistent he observation that only ccur early in the reproadult males and queen queens, are present in the colonies (Bartels 1983; Passera \& Keller 1992).

In conclusion, this study shows that males can successfully enter foreign colonies and mate with resident female sexuals. However, as in all other ant species, mating flights and dispersal are probably risky, which may account for preferential dispersal by males in colonies where they have little expectation of mating. This dispersal by males is probably one of the important components of gene flow between colonies which, in concert with preferential mating between nonrelated sexuals, appear to be an effective means of preventing inbreeding in this species exhibiting within-nest mating.

\section{ACKNOWLEDGMENTS}

We thank Andrew Bourke, Michel Genoud and Edward L. Vargo for helpful comments on the manuscript. We were supported by grants from the Swiss National Science Foundation (no 823A0283650 and 31-35584.92) (L.K.), the JanggenPöhn Stiftung (L.K.) the Ministerè francais de l'Environnement (L.P.) and the Council Régional Midi-Pyrénées (L.P.).

\section{REFERENCES}

Bartels, P. J. 1983. Polygyny and the reproductive biology of the Argentine ant. Ph.D. thesis, University of California at Santa Cruz.

Benois, A. 1973. Incidences des facteurs écologiques sur le cycle annuel et l'activité saisonnière de la fourmi d'Argentine Iridonymex humilis (Mayr) (Hymenoptera, Formicidae), dans la région d'Antibes. Insectes soc., 20, 267-296.

Crozier, R. H. 1980. Genetical structure of social insect population. In: Evolution of Social Behavior: Hypothesis and Enpirical Tests (Ed. by H. Markl), pp. 129 146. Weinheim: Verlag Chemie GmBH.

Fortelius, W., Rosengren, R., Cherix, D. \& Chautems, D. 1993. Queen recruitment in a highly polygynous supercolony of Formica lugubris Zett. (Hymenoptera, Formicidae). Oikos, 67, 193-200.

Franks, N. R. \& Hölldobler, B. 1987. Sexual competition during colony reproduction in army ants. Biol. $J$. Linn. Soc., 30, 229-243.

Hölldobler, B. \& Wilson, E. O. 1990. The Ants. Berlin: Springer-Verlag.

Kaufmann, B. \& Passera, L. 1991. Première approche du problème de la reconnaissance coloniale chez Iridomyrmex humilis (Formicidae: Dolichoderinae). Actes Coll. Insectes soc, 7, 75-82.
Kaufmann, B., Boomsma, J. J., Passera, L. \& Petersens, K. N. 1992. Mating structure and relatedness in a French population of the unicolonial ant, Iridomyrmex humilis. Insectes soc., 39, 195-200.

Keller, L., Cherix, D. \& Ulloa-Chacon, P. 1989. Description of a new artificial diet for rearing ant colonies as Iridomyrmex hmilis, Monomorium pharaonis and Wasmannia auropunctata (Hymenoptera, Formicidae) Insectes soc, , 36, 348-352.

Keller, L. \& Passera, L. 1992. Mating system, optimal number of matings, and sperm transfer in the Argentine ant Iridomymex humilis. Behav. Ecol. Sociobiol., 31, 359-366.

Keller, L. \& Passera, L. 1993. Incest avoidance, fluctuating asymmetry and the consequences of inbreeding in Iridomymex humilis, an ant with multiple queen colonies. Behav. Ecol. Sociobiol., 33, 191-199.

Newell, W. \& Barber, T. C. 1913. The Argentine ant. USDA Bureau, Entomol. Bull, 122, 1-98.

Passera, L. 1994. Characteristics of tramp species. In: Exotic Ants: Biology, Impact, and Control of Introduced Species (Ed. by D. F. Williams), pp. 23-43. Boulder, Colorado: Westview Press.

Passera, L. \& Aron, S. 1993. Social control over the survival and selection of winged virgin queens in an ant without nuptial fight: Iridomymex humilis. Ethology, 93, 225-235.

Passera, L. \& Keller, L. 1990. Loss of mating flight and shift in the pattern of carbohydrate storage in sexuals of ants (Hymenoptera; Formicidae). J. comp. Physiol. $B, 160,207-211$.

Passera, L. \& Keller, L. 1992. The period of sexual maturation and the age at mating in Iridomymex htmilis, an ant with intranidal mating. $J$. Zool., Lond., 228, 141-153.

Passera, L., Keller, L. \& Suzzoni, J. P. 1988. Control of brood male production in the Argentine ant Iridontyrmex humilis (Mayr) Insectes soc., 35, 19-33.

Peeters, C. 1991. The occurrence of sexual reproduction among ant workers. Biol. J. Linn. Soc., 44, 141-152.

Petersen, M. \& Buschinger, A, 1971. Das Begattungsverhalten der Pharaoameise Monomorium pharaonis L. Z. angew. Entomol., 68, 168-175.

Sokal, R. R. \& Rohlf, F. J. 1980. Biometry. The Principles and Practice of Statistics in Biological Research. 2nd edn. San Francisco: Freeman and Company.

Vargo, E. L. \& Passera, L. 1991. Pheromonal and behavioral queen control over the production of gynes in the Argentine ant Iridomyrmex humilis (Mayr). Behav. Ecol. Sociobiol., 28, 161-169.

Whitcomb, W. H., Bhatkar, A. \& Nickerson, J. C. 1973. Predators of Solenopsis invicta (Hym. Formicidae) queens prior to successful colony establishment. Environ. Entomol, 2, 1101-1103.

Yamauchi, K., Furukawa, T., Kinomura, K. Takamine, H. \& Tsuji, K. 1991. Secondary polygyny by inbred wingless sexuals in the dolichoderine ant Technomyrmex albipes. Behav. Ecol. Sociobiol., 29, 313-319.

Yamauchi, K., Kinomura, K. \& Miyake, S. 1981. Sociobiological studies of the polygynic ant Lasius sakagamii. 1. General features of its polydomous system. Insectes soc., 28, 279-296. 